Kragujevac Journal of Mathematics

Volume 44(2) (2020), Pages 237-249.

\title{
SOME RESULTS ON SUPER EDGE-MAGIC DEFICIENCY OF GRAPHS
}

\author{
M. IMRAN ${ }^{1,2}$, A. Q. BAIG ${ }^{3}$, AND A. S. FEŇOVČÍKOVÁ ${ }^{4}$
}

\begin{abstract}
An edge-magic total labeling of a graph $G$ is a bijection $f$ : $V(G) \cup E(G) \rightarrow\{1,2, \ldots,|V(G)|+|E(G)|\}$, where there exists a constant $k$ such that $f(u)+f(u v)+f(v)=k$, for every edge $u v \in E(G)$. Moreover, if the vertices are labeled with the numbers $1,2, \ldots,|V(G)|$ such a labeling is called a super edge-magic total labeling. The super edge-magic deficiency of a graph $G$, denoted by $\mu_{s}(G)$, is the minimum nonnegative integer $n$ such that $G \cup n K_{1}$ has a super edge-magic total labeling or is defined to be $\infty$ if there exists no such $n$.

In this paper we study the super edge-magic deficiencies of two types of snake graph and a prism graph $D_{n}$ for $n \equiv 0(\bmod 4)$. We also give an exact value of super edge-magic deficiency for a ladder $P_{n} \times K_{2}$ with 1 pendant edge attached at each vertex of the ladder, for $n$ odd, and an exact value of super edge-magic deficiency for a square of a path $P_{n}$ for $n \geq 3$.
\end{abstract}

\section{INTRODUCTION}

In this paper, we consider only finite, simple and undirected graphs. We denote the vertex set and edge set of a graph $G$ by $V(G)$ and $E(G)$, respectively. Let $|V(G)|=p$ and $|E(G)|=q$.

An edge-magic total labeling of a graph $G$ is a bijection $f: V(G) \cup E(G) \rightarrow$ $\{1,2, \ldots, p+q\}$, where there exists a constant $k$ such that

$$
f(u)+f(u v)+f(v)=k,
$$

for every edge $u v \in E(G)$. The constant $k$ is called a magic constant. An edge-magic total labeling $f$ is called super edge-magic total if the vertices are labeled with the

\footnotetext{
Key words and phrases. Super edge-magic total labeling, super edge-magic deficiency, block graph, snake graph, prism, corona of graphs, square of graph.

DOI 10.46793/KgJMat2002.237I

Received: September 21, 2017.

Accepted: April 12, 2018.
} 
smallest possible labels, i.e., with the numbers $1,2, \ldots, p$. A graph that admits a (super) edge-magic total labeling is called (super) edge-magic total.

The concept of edge-magic total labeling was given by Kotzig and Rosa [8]. Super edge-magic total labelings were originally defined by Enomoto et al. in [3]. However Acharya and Hegde had introduced in [1] the concept of strongly indexable graphs that is equivalent to the one of super edge-magic total labeling.

Kotzig and Rosa [8] proved that for any graph $G$ there exists an edge-magic graph $H$ such that $H \cong G \cup n K_{1}$ for some nonnegative integer $n$. This fact leads to the concept of edge-magic deficiency of a graph $G$, which is the minimum nonnegative integer $n$ such that $G \cup n K_{1}$ is edge-magic total and it is denoted by $\mu(G)$. In particular,

$$
\mu(G)=\min \left\{n \geq 0: G \cup n K_{1} \text { is edge-magic total }\right\} .
$$

In the same paper, Kotzig and Rosa gave an upper bound for the edge-magic deficiency of a graph $G$ with $n$ vertices,

$$
\mu(G) \leq F_{n+2}-2-n-\frac{n(n-1)}{2},
$$

where $F_{n}$ is the $n$th Fibonacci number.

Motivated by Kotzig and Rosa's concept of edge-magic deficiency, Figueroa-Centeno, Ichishima and Muntaner-Batle [5] defined a similar concept for the super edge-magic total labelings. The super edge-magic deficiency of a graph $G$, denoted by $\mu_{s}(G)$, is the minimum nonnegative integer $n$ such that $G \cup n K_{1}$ has a super edge-magic total labeling, or is defined to be $\infty$ if there exists no such $n$. More precisely, if

$$
M(G)=\left\{n \geq 0: G \cup n K_{1} \text { is a super edge-magic total graph }\right\},
$$

then

$$
\mu_{s}(G)= \begin{cases}\min M(G), & \text { if } M(G) \neq \emptyset \\ \infty, & \text { if } M(G)=\emptyset\end{cases}
$$

It is easy to see that for every graph $G$ it holds

$$
\mu(G) \leq \mu_{s}(G)
$$

In $[5,7]$ Figueroa-Centeno, Ichishima and Muntaner-Batle found the exact values of the super edge-magic deficiencies of several classes of graphs, such as cycles, complete graphs, 2-regular graphs and complete bipartite graphs $K_{2, m}$. They also proved that all forests have finite deficiency. In particular, they proved that

$$
\mu_{s}\left(n K_{2}\right)= \begin{cases}0, & \text { if } n \text { is odd } \\ 1, & \text { if } n \text { is even }\end{cases}
$$

In [10] Ngurah, Simanjuntak and Baskoro gave some upper bounds for the super edge-magic deficiency of fans, double fans and wheels. In [6] Figueroa-Centeno, 
Ichishima and Muntaner-Batle proved

$$
\mu_{s}\left(P_{m} \cup K_{1, n}\right)= \begin{cases}1, & \text { if } m=2 \text { and } n \text { is odd or } m=3 \text { and } n \neq 0 \quad(\bmod 3), \\ 0, & \text { otherwise. }\end{cases}
$$

In the same paper, they showed that

$$
\mu_{s}\left(K_{1, m} \cup K_{1, n}\right)= \begin{cases}0, & \text { if } m \text { is a multiple of } n+1 \text { or } n \text { is a multiple of } m+1, \\ 1, & \text { otherwise. }\end{cases}
$$

They also conjectured that every forest with two components has super edge-magic deficiency less than or equal to 1. Baig, Baskoro and Semaničová-Feňovčíková [2] have determined the super edge magic deficiency of a star forest. Santhosh and Singh [11] studied the corona product of $K_{2}$ and $C_{n}$ and they showed that $\mu_{s}\left(K_{2} \odot C_{n}\right) \leq \frac{n-3}{2}$, for $n$ odd at least 3 .

In this paper we study the super edge-magic deficiencies for several classes of graphs. We give upper bounds for the super edge-magic deficiencies of two types of snake graph and for prism graph $D_{n}$ for $n \equiv 0(\bmod 4)$. We also give an exact value of super edge-magic deficiency for a ladder $P_{n} \times K_{2}$ with 1 pendant edge attached at each vertex of the ladder, for $n$ odd, and an exact value of super edge-magic deficiency for a square of a path $P_{n}$ for every positive integer $n, n \geq 3$.

To prove the results presented in this paper, we frequently use the following lemma.

Lemma 1.1. [4] A graph $G$ with $p$ vertices and $q$ edges is super edge-magic total if and only if there exists a bijective function $f: V(G) \rightarrow\{1,2, \ldots, p\}$ such that the set $\{f(u)+f(v): u v \in E(G)\}$ consists of $q$ consecutive integers. In such a case, $f$ extends to a super edge-magic total labeling of $G$.

\section{UPPER BOUNDS}

In graph theory a block graph is a graph in which every bi-connected component (block) is a clique. Block graphs are sometimes erroneously said to be "Husimi trees", but that name more properly refers to cactus graphs, graphs in which every nontrivial bi-connected component is a cycle. In graph theory block graphs may be described as the intersection graphs of the blocks of arbitrary undirected graphs.

Let $G$ be a graph and $u$ and $v$ are two fixed vertices in $G$. The $G^{n}$-snake is a graph obtained from $n$ copies of $G$ by identifying the vertex corresponding to the vertex $v$ in the $i$ th copy of $G$ with the vertex corresponding to the vertex $u$ in the $(i+1)$ th copy of $G$, for $i=1,2, \ldots, n-1$. The wheel $W_{k}, k \geq 3$ is a graph obtained by joining every vertex of a cycle $C_{k}$ with a new vertex.

In the following theorem we will deal with the super edge-magic deficiency of $W_{4}^{n}$-snake. Let us denote the vertex set and the edge set of $W_{4}^{n}$-snake such that

$$
\begin{aligned}
V\left(W_{4}^{n} \text {-snake }\right)= & \left\{x_{i}: i=1,2, \ldots, 2 n\right\} \cup\left\{y_{i}: i=1,2, \ldots, n\right\} \\
& \cup\left\{z_{i}: i=1,2, \ldots, n+1\right\},
\end{aligned}
$$




$$
\begin{aligned}
E\left(W_{4}^{n} \text {-snake }\right)= & \left\{x_{i} x_{n+i}: i=1,2, \ldots, n\right\} \cup\left\{z_{i} z_{i+1}: i=1,2, \ldots, n\right\} \\
& \cup\left\{x_{i} z_{i}, x_{n+i} z_{i+1}: i=1,2, \ldots, n\right\} \\
& \cup\left\{y_{i} x_{i}, y_{i} x_{n+i}: i=1,2, \ldots, n\right\} \\
& \cup\left\{y_{i} z_{i}, y_{i} z_{i+1}: i=1,2, \ldots, n\right\} .
\end{aligned}
$$

Theorem 2.1. The graph $W_{4}^{n}$-snake has super edge-magic deficiency at most 1 .

Proof. Let us denote the vertices and edges of $G \cong W_{4}^{n} \cup K_{1}$ such that $V(G)=$ $V\left(W_{4}^{n}\right.$-snake $) \cup\{v\}$ and $E(G)=E\left(W_{4}^{n}\right.$-snake $)$. The graph $G$ has $4 n+2$ vertices and $8 n$ edges.

We define the vertex labeling $f$ of $G$ in the following way

$$
\begin{aligned}
f\left(x_{i}\right) & =4 i-3, \quad \text { if } i=1,2, \ldots, n, \\
f\left(x_{n+i}\right) & =4 i-1, \quad \text { if } i=1,2, \ldots, n, \\
f\left(y_{i}\right) & =4 i, \quad \text { if } i=1,2, \ldots, n, \\
f\left(z_{i}\right) & =4 i-2, \quad \text { if } i=1,2, \ldots, n+1, \\
f(v) & =4 n+1 .
\end{aligned}
$$

It is easy to see that the vertices of $G$ are labeled with the numbers $1,2,3, \ldots, 4 n+2$ as the sets of vertex labels are

$$
\begin{aligned}
\left\{f\left(x_{i}\right): i=1,2,3, \ldots, n\right\} & =\{1,5,9, \ldots, 4 n-3\}, \\
\left\{f\left(z_{i}\right): i=1,2,3, \ldots, n, n+1\right\} & =\{2,6,10, \ldots, 4 n-2,4 n+2\}, \\
\left\{f\left(x_{i}\right): i=n+1, n+2, n+3, \ldots, 2 n\right\} & =\{3,7,11, \ldots, 4 n-1\}, \\
\left\{f\left(y_{i}\right): i=1,2,3, \ldots, n\right\} & =\{4,8,12, \ldots, 4 n\}, \\
f(v) & =4 n+1 .
\end{aligned}
$$

Next we will count the edge sums of the edges in the blocks. For $i=1,2, \ldots, n$ it holds

$$
\begin{aligned}
f\left(x_{i}\right)+f\left(z_{i}\right) & =(4 i-3)+(4 i-2)=8 i-5, \\
f\left(x_{i}\right)+f\left(x_{i+n}\right) & =(4 i-3)+(4 i-1)=8 i-4, \\
f\left(x_{i}\right)+f\left(y_{i}\right) & =(4 i-3)+4 i=8 i-3, \\
f\left(y_{i}\right)+f\left(z_{i}\right) & =4 i+(4 i-2)=8 i-2, \\
f\left(x_{i+n}\right)+f\left(y_{i}\right) & =(4 i-1)+4 i=8 i-1, \\
f\left(z_{i}\right)+f\left(z_{i+1}\right) & =(4 i-2)+(4(i+1)-2)=8 i, \\
f\left(x_{i+n}\right)+f\left(z_{i+1}\right) & =(4 i-1)+(4(i+1)-2)=8 i+1, \\
f\left(y_{i}\right)+f\left(z_{i+1}\right) & =4 i+(4(i+1)-2)=8 i+2 .
\end{aligned}
$$

It means that the edge sums are consecutive integers $3,4, \ldots, 8 n+2$. According to Lemma 1.1 the labeling $f$ can be extended to a super edge-magic total labeling of $G$ with magic constant $12 n+5$. 
A graph is called a cactus graph if every block is either a cycle or a complete graph $K_{2}$. Next we will deal with a special type of a cactus graph called an alternate quadrilateral snake. An alternate quadrilateral snake $A\left(C_{4}^{n}\right)$ is obtained from a path $x_{1} x_{2} \ldots x_{n}$ by joining the vertices $x_{i}, x_{i+1}$, for every odd $i$, to new vertices $y_{i}, y_{i+1}$, respectively and then joining $y_{i}$ and $y_{i+1}$. That is every alternate edge of the path is replaced by a cycle $C_{4}$. More precisely, the vertex set and the edge set of $A\left(C_{4}^{n}\right)$ are the following

$$
V\left(A\left(C_{4}^{n}\right)\right)=\left\{x_{i}, y_{i}: i=1,2, \ldots, n\right\}
$$

and

$$
\begin{aligned}
E\left(A\left(C_{4}^{n}\right)\right)= & \left\{x_{i} x_{i+1}: i=1,2, \ldots, n-1\right\} \cup\left\{x_{i} y_{i}: i=1,2, \ldots, n\right\} \\
& \cup\left\{y_{i} y_{i+1}: i=1,3, \ldots, n-1\right\} .
\end{aligned}
$$

Theorem 2.2. For every even positive integer $n, n \geq 4$, for super edge-magic deficiency of the alternate quadrilateral snake $A\left(C_{4}^{n}\right)$ we have

$$
\mu_{s}\left(A\left(C_{4}^{n}\right)\right) \leq \frac{n}{2}
$$

Proof. Let $n$ be an even positive integer. Let us denote the vertex set and the edge set of $G \cong A\left(C_{4}^{n}\right) \cup \frac{n}{2} K_{1}$ as follows $V(G)=V\left(A\left(C_{4}^{n}\right)\right) \cup\left\{v_{i}: i=1,2, \ldots, \frac{n}{2}\right\}$ and $E(G)=E\left(A\left(C_{4}^{n}\right)\right)$.

We define the vertex labeling of the graph $G$ in the following way

$$
\begin{aligned}
& f\left(x_{i}\right)= \begin{cases}i, & \text { if } i=1,3, \ldots, n-1, \\
n+\frac{3 i}{2}, & \text { if } i=2,4, \ldots, n,\end{cases} \\
& f\left(y_{i}\right)= \begin{cases}n+\frac{3 i-1}{2}, & \text { if } i=1,3, \ldots, n-1, \\
i, & \text { if } i=2,4, \ldots, n .\end{cases}
\end{aligned}
$$

The remaining $\frac{n}{2}$ numbers $n+2, n+5, \ldots, \frac{5 n}{2}-1$ are used to label the isolated vertices $v_{1}, v_{2}, \ldots, v_{\frac{n}{2}}$ of the graph $G$ arbitrary.

It is easy to see that $f$ is a bijection from the vertex set of $G$ onto the set of integers $1,2, \ldots, \frac{5 n}{2}$.

For the edge sums we have the following. The edge sum of the edges $x_{i} y_{i}, y_{i} y_{i+1}$, $x_{i} x_{i+1}$ and $y_{i+1} x_{i+1}$, for $i=1,3, \ldots, n-1$, are

$$
\begin{aligned}
f\left(x_{i}\right)+f\left(y_{i}\right) & =i+\left(n+\frac{3 i-1}{2}\right)=n+\frac{5 i-1}{2}, \\
f\left(y_{i}\right)+f\left(y_{i+1}\right) & =\left(n+\frac{3 i-1}{2}\right)+(i+1)=n+\frac{5 i-1}{2}+1, \\
f\left(x_{i}\right)+f\left(x_{i+1}\right) & =i+\left(n+\frac{3(i+1)}{2}\right)=n+\frac{5 i-1}{2}+2, \\
f\left(x_{i+1}\right)+f\left(y_{i+1}\right) & =\left(n+\frac{3(i+1)}{2}\right)+(i+1)=n+\frac{5 i-1}{2}+3 .
\end{aligned}
$$


The edge sum of the edge $x_{i+1} x_{i+2}$, for $i=1,3, \ldots, n-3$, is

$$
f\left(x_{i+1}\right)+f\left(x_{i+2}\right)=\left(n+\frac{3(i+1)}{2}\right)+(i+2)=n+\frac{5 i-1}{2}+4 .
$$

Moreover, for $i=1,3, \ldots, n-3$, we have

$$
f\left(x_{i+2}\right)+f\left(y_{i+2}\right)=(i+2)+\left(n+\frac{3(i+2)-1}{2}\right)=n+\frac{5 i-1}{2}+5 .
$$

Hence the edge sums are consecutive integers $n+2, n+3, \ldots, \frac{7 n}{2}$. Thus, according to Lemma 1.1, the labeling $f$ can be extended to the super edge-magic total labeling of $G$ with the magic constant $6 n+1$.

The graph $A\left(C_{4}^{2}\right)$ is isomorphic to the cycle $C_{4}$. Figueroa-Centeno, Ichishima and Muntaner-Batle [5] proved that $\mu_{s}\left(C_{4}\right)=1$.

A prism graph $D_{n}$, sometimes also called a circular ladder graph, is a graph corresponding to the skeleton of an $n$-prism. Prism graphs are both planar and polyhedral. An $n$-prism graph consist of $2 n$ vertices and $3 n$ edges, which is equivalent to generalized Petersen graph $P_{n, 1}$. The $n$-prism is isomorphic to circulant graph $C i_{2 n}(2, n)$ for odd $n$, and can be showed by rotating the inner cycle by $180^{\circ}$, and its radius is equal to that of the outer cycle in the top embedding above. In addition, for odd $n, D_{n}$ is isomorphic to $C i_{2 n}(4, n), C i_{2 n}(6, n), \ldots, C i_{2 n}(n-1, n)$. The prism $D_{n}$ is isomorphic to the Cartesian product $C_{n} \times K_{2}$, where $C_{n}$ is the cycle on $n$ vertices and $K_{2}$ is the complete graph of order 2. The prism graph $D_{n}$ is equivalent to the Cayley graph of the dihedral group $D_{n}$, with respect to the generating set $\left\{x, x^{-1}, y\right\}$.

We denote the vertices and edges of $D_{n}$ such that

$$
V\left(D_{n}\right)=\left\{x_{i}, y_{i}: i=1,2, \ldots, n\right\}
$$

and

$$
E\left(D_{n}\right)=\left\{x_{i} x_{i+1}, y_{i} y_{i+1}: i=1,2, \ldots, n-1\right\} \cup\left\{x_{1} x_{n}, y_{1} y_{n}\right\} \cup\left\{x_{i} y_{i}: i=1,2, \ldots, n\right\} .
$$

The cardinality of the vertex set and the edge set of $D_{n}$ is $2 n$ and $3 n$, respectively.

In [4] Figueroa-Centeno, Ichishima and Muntaner-Batle proved that for $n$ odd the graph $D_{n}$ is super edge-magic total. Ngurah and Baskoro [9] showed that for $n$ even the prism $D_{n}$ is not edge-magic total. In the following theorem we are dealing with the case when $n$ is divisible by 4 .

Theorem 2.3. Let $n$ be a positive integer, $n \equiv 0(\bmod 4)$. The super edge-magic deficiency of $D_{n}$ is

$$
\mu_{s}\left(D_{n}\right) \leq \frac{3 n}{2}-1
$$

Proof. Let $n$ be a positive integer, $n \equiv 0(\bmod 4)$. Let us denote the isolated vertices of $G \cong D_{n} \cup\left(\frac{3 n}{2}-1\right) K_{1}$ by the symbols $v_{1}, v_{2}, \ldots, v_{\frac{3 n}{2}-1}$. 
We define the vertex labeling $f$ of $G$ in the following way.

$$
\begin{aligned}
& f\left(x_{i}\right)= \begin{cases}\frac{i+1}{2}, & \text { if } i=1,3, \ldots, n-1, \\
\frac{9 n}{4}-1+\frac{i}{2}, & \text { if } i=2,4, \ldots, \frac{n}{2} \\
\frac{5 n}{4}+\frac{i}{2}, & \text { if } i=\frac{n}{2}+2, \frac{n}{2}+4, \ldots, n,\end{cases} \\
& f\left(y_{i}\right)= \begin{cases}\frac{11 n}{4}, & \text { if } i=1, \\
\frac{n+\frac{i}{2},}{13 n}+\frac{i-3}{2} & \text { if } i=3,5, \ldots, \frac{n}{2}+1, \\
\frac{9 n}{4}+\frac{i-1}{2} & \text { if } i=\frac{n}{2}+3, \frac{n}{2}+5, \ldots n-1,\end{cases}
\end{aligned}
$$

and the vertices $v_{i}, i=1,2, \ldots, \frac{3 n}{2}-1$ are labeled arbitrary with $\frac{3 n}{2}-1$ unused numbers from the set $\left\{1,2, \ldots, \frac{7 n}{2}-1\right\}$. It is not difficult to check that the vertices $v_{i}, i=1,2, \ldots, \frac{3 n}{2}-1$ are labeled with the numbers $\frac{n}{2}+1, \frac{n}{2}+2, \ldots, \frac{3 n}{2}, \frac{7 n}{4}+1, \frac{7 n}{4}+$ $2, \ldots, \frac{9 n}{4}-1, \frac{5 n}{2}, \frac{11 n}{4}+1, \frac{11 n}{4}+2, \ldots, \frac{13 n}{4}-1$.

Next we prove that the edge sums are consecutive integers. Indeed, we have

$$
\begin{aligned}
f\left(x_{1}\right)+f\left(x_{n}\right) & =\frac{1+1}{2}+\left(\frac{5 n}{4}+\frac{n}{2}\right)=\frac{7 n}{4}+1 \\
f\left(x_{\frac{n}{2}+1}\right)+f\left(x_{\frac{n}{2}+2}\right) & =\frac{\left(\frac{n}{2}+1\right)+1}{2}+\left(\frac{5 n}{4}+\frac{\frac{n}{2}+2}{2}\right)=\frac{7 n}{4}+2, \\
f\left(x_{\frac{n}{2}+2}\right)+f\left(x_{\frac{n}{2}+3}\right) & =\left(\frac{5 n}{4}+\frac{\frac{n}{2}+2}{2}\right)+\frac{\left(\frac{n}{2}+1\right)+3}{2}=\frac{7 n}{4}+3, \\
& \vdots \\
f\left(x_{n-1}\right)+f\left(x_{n}\right) & =\frac{(n-1)+1}{2}+\left(\frac{5 n}{4}+\frac{n}{2}\right)=\frac{9 n}{4}, \\
f\left(x_{1}\right)+f\left(x_{2}\right) & =\frac{1+1}{2}+\left(\frac{9 n}{4}-1+\frac{2}{2}\right)=\frac{9 n}{4}+1, \\
f\left(x_{2}\right)+f\left(x_{3}\right) & =\left(\frac{9 n}{4}-1+\frac{2}{2}\right)+\frac{3+1}{2}=\frac{9 n}{4}+2, \\
& \vdots \\
f\left(x_{\frac{n}{2}}\right)+f\left(x_{\frac{n}{2}+1}\right) & =\left(\frac{9 n}{4}-1+\frac{\frac{n}{2}}{2}\right)+\frac{\left(\frac{n}{2}+1\right)+1}{2}=\frac{11 n}{4},
\end{aligned}
$$




$$
\begin{aligned}
& f\left(x_{1}\right)+f\left(y_{1}\right)=\frac{1+1}{2}+\frac{11 n}{4}=\frac{11 n}{4}+1, \\
& f\left(x_{\frac{n}{2}+2}\right)+f\left(y_{\frac{n}{2}+2}\right)=\left(\frac{5 n}{4}+\frac{\frac{n}{2}+2}{2}\right)+\left(n+\frac{\frac{n}{2}+2}{2}\right)=\frac{11 n}{4}+2, \\
& f\left(x_{\frac{n}{2}+3}\right)+f\left(y_{\frac{n}{2}+3}\right)=\frac{\left(\frac{n}{2}+1\right)+3}{2}+\left(\frac{9 n}{4}+\frac{\left(\frac{n}{2}+3\right)-1}{2}\right)=\frac{11 n}{4}+3, \\
& f\left(x_{n}\right)+f\left(y_{n}\right)=\left(\frac{5 n}{4}+\frac{n}{2}\right)+\left(n+\frac{n}{2}\right)=\frac{13 n}{4}, \\
& f\left(x_{2}\right)+f\left(y_{2}\right)=\left(\frac{9 n}{4}-1+\frac{2}{2}\right)+\left(n+\frac{2}{2}\right)=\frac{13 n}{4}+1, \\
& f\left(x_{3}\right)+f\left(y_{3}\right)=\frac{3+1}{2}+\left(\frac{13 n}{4}+\frac{3-3}{2}\right)=\frac{13 n}{4}+2, \\
& f\left(x_{\frac{n}{2}+1}\right)+f\left(y_{\frac{n}{2}+1}\right)=\frac{\left(\frac{n}{2}+1\right)+1}{2}+\left(\frac{13 n}{4}+\frac{\left(\frac{n}{2}+1\right)-3}{2}\right)=\frac{15 n}{4}, \\
& f\left(y_{1}\right)+f\left(y_{2}\right)=\frac{11 n}{4}+\left(n+\frac{2}{2}\right)=\frac{15 n}{4}+1, \\
& f\left(y_{\frac{n}{2}+2}\right)+f\left(y_{\frac{n}{2}+3}\right)=\left(n+\frac{\frac{n}{2}+2}{2}\right)+\left(\frac{9 n}{4}+\frac{\left(\frac{n}{2}+3\right)-1}{2}\right)=\frac{15 n}{4}+2, \\
& f\left(y_{\frac{n}{2}+3}\right)+f\left(y_{\frac{n}{2}+4}\right)=\left(\frac{9 n}{4}+\frac{\left(\frac{n}{2}+3\right)-1}{2}\right)+\left(n+\frac{\frac{n}{2}+4}{2}\right)=\frac{15 n}{4}+3 \text {, } \\
& f\left(y_{1}\right)+f\left(y_{n}\right)=\frac{11 n}{4}+\left(n+\frac{n}{2}\right)=\frac{17 n}{4}, \\
& f\left(y_{2}\right)+f\left(y_{3}\right)=\left(n+\frac{2}{2}\right)+\left(\frac{13 n}{4}+\frac{3-3}{2}\right)=\frac{17 n}{4}+1, \\
& f\left(y_{3}\right)+f\left(y_{4}\right)=\left(\frac{13 n}{4}+\frac{3-3}{2}\right)+\left(n+\frac{4}{2}\right)=\frac{17 n}{4}+2, \\
& f\left(y_{\frac{n}{2}+1}\right)+f\left(y_{\frac{n}{2}+2}\right)=\left(\frac{13 n}{4}+\frac{\frac{n}{2}+1-3}{2}\right)+\left(n+\frac{\frac{n}{2}+2}{2}\right)=\frac{19 n}{4} .
\end{aligned}
$$


Hence the edge sums are the numbers $\frac{7 n}{4}+1, \frac{7 n}{4}+2, \ldots, \frac{19 n}{4}$. According to Lemma 1.1 the labeling $f$ can be extended to the super edge-magic total labeling of $G$ with the magic constant $\frac{33 n}{4}$.

\section{Exact Values}

If $G$ has order $p$, the corona of $G$ with $H$, denoted by $G \odot H$, is the graph obtained by taking one copy of $G$ and $p$ copies of $H$ and joining the $i$ th vertex of $G$ with an edge to every vertex in the $i$ th copy of $H$.

Let us consider the Cartesian product $P_{n} \times K_{2}$, where $P_{n}$ is the path on $n$ vertices and $K_{2}$ is the complete graph of order 2. This graph is also called a ladder. In this section we deal with the super edge-magic deficiency of a ladder $P_{n} \times K_{2}$ with 1 pendant edge attached at each vertex of $P_{n} \times K_{2}$, i.e., the corona $\left(P_{n} \times K_{2}\right) \odot K_{1}$.

Theorem 3.1. For every odd positive integer $n$ the graph $\left(P_{n} \times K_{2}\right) \odot K_{1}$ is super edge-magic total, i.e.,

$$
\mu_{s}\left(\left(P_{n} \times K_{2}\right) \odot K_{1}\right)=0
$$

Proof. Let $n$ be a positive odd integer. We denote the vertex set and the edge set of $G \cong\left(P_{n} \times K_{2}\right) \odot K_{1}$ as follows

$$
\begin{aligned}
& V(G)=\left\{x_{i}, s_{i}, b_{i}, d_{i}: i=1,2, \ldots, n\right\} \\
& E(G)=\left\{x_{i} s_{i}, x_{i} b_{i}, s_{i} d_{i}: i=1,2, \ldots, n\right\} \cup\left\{x_{i} x_{i+1}, s_{i} s_{i+1}: i=1,2, \ldots, n-1\right\} .
\end{aligned}
$$

The graph $G$ is of order $4 n$ and of size $5 n-2$.

For $n \geq 5$ we define the vertex labeling $f$ of $G$ such that

$$
\begin{aligned}
& f\left(x_{i}\right)= \begin{cases}\frac{4 n+1+i}{2}, & \text { if } i=1,3, \ldots, n, \\
\frac{5 n+1+i}{2}, & \text { if } i=2,4, \ldots, n-1,\end{cases} \\
& f\left(s_{i}\right)= \begin{cases}\frac{3 n+i}{2}, & \text { if } i=1,3, \ldots, n, \\
\frac{2 n+i}{2}, & \text { if } i=2,4, \ldots, n-1,\end{cases} \\
& f\left(b_{i}\right)= \begin{cases}\frac{n-1}{2}, & \text { if } i=1, \\
\frac{6 n+i}{2}, & \text { if } i=2,4, \ldots, n-1, \\
\frac{7 n+i}{2}, & \text { if } i=3,5, \ldots, n-2, \\
n, & \text { if } i=n,\end{cases}
\end{aligned}
$$




$$
f\left(d_{i}\right)= \begin{cases}\frac{n-1,}{2 n+1} & \text { if } i=1 \\ 4 n, & \text { if } i=2, \\ \frac{n-3+i}{2}, & \text { if } i=3 \\ \frac{i-3}{2}, & \text { if } i=5,7, \ldots, n .\end{cases}
$$

It is easy to see that the vertices of $G$ are labeled with the numbers $1,2, \ldots, 4 n$ as the sets of vertex labels are the following ones.

$$
\begin{aligned}
& \left\{f\left(s_{i}\right): i=1,2, \ldots, n\right\}=\{n+1, n+2, \ldots, 2 n\}, \\
& \left\{f\left(x_{i}\right): i=1,2, \ldots, n\right\}=\{2 n+1,2 n+2, \ldots, 3 n\}, \\
& \left\{f\left(b_{i}\right): i=1,2, \ldots, n\right\}=\left\{\frac{n-1}{2}, n, 3 n+1,3 n+2, \ldots, \frac{7 n-1}{2}, \frac{7 n+3}{2}, \frac{7 n+5}{2}, \ldots, 4 n-1\right\}, \\
& \left\{f\left(d_{i}\right): i=1,2, \ldots, n\right\}=\left\{1,2, \ldots, \frac{n-3}{2}, \frac{n+1}{2}, \frac{n+3}{2}, \ldots, n-2, n-1, \frac{7 n+1}{2}, 4 n\right\} .
\end{aligned}
$$

Thus $f$ is a bijection.

The edge sums under the labeling $f$ are consecutive integers from the set $\left\{\frac{3 n+5}{2}, \frac{3 n+7}{2}+1, \ldots, \frac{13 n-1}{2}\right\}$ since we have

$$
\begin{aligned}
f\left(s_{4} d_{4}\right) & =\frac{2 n+4}{2}+\frac{n-3+4}{2}=\frac{3 n+5}{2}, \\
f\left(s_{5} d_{5}\right) & =\frac{3 n+5}{2}+\frac{5-3}{2}=\frac{3 n+7}{2}, \\
& \vdots \\
f\left(s_{n} d_{n}\right) & =\frac{3 n+n}{2}+\frac{n-3}{2}=\frac{5 n-3}{2}, \\
f\left(s_{1} d_{1}\right) & =\frac{3 n+1}{2}+(n-1)=\frac{5 n-1}{2}, \\
f\left(x_{1} b_{1}\right) & =\frac{4 n+1+1}{2}+\frac{n-1}{2}=\frac{5 n+1}{2}, \\
f\left(s_{1} s_{2}\right) & =\frac{3 n+1}{2}+\frac{2 n+2}{2}=\frac{5 n+3}{2}, \\
f\left(s_{2} s_{3}\right) & =\frac{2 n+2}{2}+\frac{3 n+3}{2}=\frac{5 n+5}{2}, \\
& \vdots \quad \frac{2 n+(n-1)}{2}+\frac{3 n+n}{2}=\frac{7 n-1}{2}, \\
f\left(s_{n-1} s_{n}\right) & \frac{2 n+1}{2}, \\
f\left(x_{n} b_{n}\right) & =\frac{4 n+1+n}{2}+n=\frac{7 n+1}{2},
\end{aligned}
$$




$$
\begin{aligned}
& f\left(s_{1} x_{1}\right)=\frac{3 n+1}{2}+\frac{4 n+1+1}{2}=\frac{7 n+3}{2}, \\
& f\left(s_{2} x_{2}\right)=\frac{2 n+2}{2}+\frac{5 n+1+2}{2}=\frac{7 n+5}{2}, \\
& f\left(s_{n} x_{n}\right)=\frac{3 n+n}{2}+\frac{4 n+1+n}{2}=\frac{9 n+1}{2}, \\
& f\left(s_{2} d_{2}\right)=\frac{2 n+2}{2}+\frac{7 n+1}{2}=\frac{9 n+3}{2}, \\
& f\left(x_{1} x_{2}\right)=\frac{4 n+1+1}{2}+\frac{5 n+1+2}{2}=\frac{9 n+5}{2}, \\
& f\left(x_{2} x_{3}\right)=\frac{5 n+1+2}{2}+\frac{4 n+1+3}{2}=\frac{9 n+7}{2}, \\
& f\left(x_{n-1} x_{n}\right)=\frac{5 n+1+(n-1)}{2}+\frac{4 n+1+n}{2}=\frac{11 n+1}{2}, \\
& f\left(s_{3} d_{3}\right)=\frac{3 n+3}{2}+4 n=\frac{11 n+3}{2}, \\
& f\left(x_{2} b_{2}\right)=\frac{5 n+1+2}{2}+\frac{6 n+2}{2}=\frac{11 n+5}{2}, \\
& f\left(x_{3} b_{3}\right)=\frac{4 n+1+3}{2}+\frac{7 n+3}{2}=\frac{11 n+7}{2}, \\
& f\left(x_{n-1} b_{n-1}\right)=\frac{5 n+1+(n-1)}{2}+\frac{6 n+(n-1)}{2}=\frac{13 n-1}{2} .
\end{aligned}
$$

According to Lemma 1.1 the labeling $f$ can be extended to the super edge-magic total labeling of $G \cong\left(P_{n} \times K_{2}\right) \odot K_{1}$, for $n \geq 5$ with the magic constant $\frac{21 n+1}{2}$.

On Figures 1 and 2 are illustrated super edge-magic total labelings of $\left(P_{1} \times K_{2}\right) \odot$ $K_{1} \cong P_{4}$ and $\left(P_{3} \times K_{2}\right) \odot K_{1}$, respectively.

This concludes the proof.

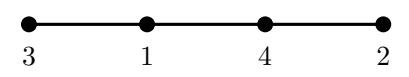

Figure 1. A super edge-magic total labeling of $\left(P_{1} \times K_{2}\right) \odot K_{1} \cong P_{4}$.

\section{Conclusion}

In this paper we have dealt with the problem of finding super edge-magic deficiency of graphs. We were trying to find the exact values of super edge-magic deficiencies 


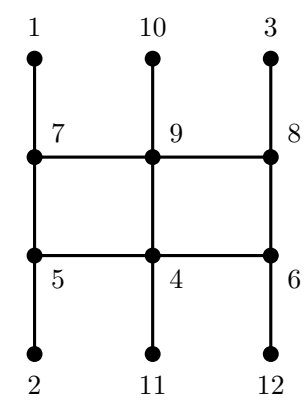

Figure 2. A super edge-magic total labeling of $\left(P_{3} \times K_{2}\right) \odot K_{1}$.

of some graphs or to find the upper bound of this parameter for several classes of graphs.

In Theorem 2.3 we described the upper bound of the super edge-magic deficiency of prism $D_{n}$ for $n \equiv 0(\bmod 4)$. As it is known, see [4], that for $n$ odd the prism $D_{n}$ is super edge-magic. To conclude the problem of finding the super edge-magic deficiency of prism $D_{n}$ also for $n$ even, for further investigation we state the following open problem.

Open Problem. Find the super edge-magic deficiency of prism $D_{n}$, for $n \equiv 2$ $(\bmod 4)$.

Acknowledgements. This research is supported by the Start-up Research Grant 2016 of United Arab Emirates University (UAEU), Al Ain, United Arab Emirates via Grant No. G00002233 and UPAR Grant of UAEU via Grant No. G00002590.

Also this research is supported by Slovak Science and Technology Assistance Agency under the contract No. APVV-15-0116 and by VEGA 1/0233/18.

\section{REFERENCES}

[1] B. D. Acharya and S. M. Hegde, Strongly indexable graphs, Discrete Math. 93 (1991), 123-129.

[2] A. Q. Baig, E. T. Baskoro and A. Semaničová-Feňovčíková, On the super edge-magic deficiency of a star forest, Ars Combin. 115 (2014), 3-12.

[3] H. Enomoto, A. S. Lladó, T. Nakamigawa and G. Ringel, Super edge-magic graphs, SUT J. Math. 34 (1998), 105-109.

[4] R. M. Figueroa, R. Ichishima and F. A. Muntaner-Batle, The place of super edge-magic labeling among other classes of labeling, Discrete Math. 231 (2001), 153-168.

[5] R. M. Figueroa-Centeno, R. Ichishima and F. A. Muntaner-Batle, On the super edge magic deficiency of graphs, Electron. Notes Discrete Math. 11 (2002), 299-314.

[6] R. M. Figueroa-Centeno, R. Ichishima and F. A. Muntaner-Batle, Some new results on the super edge-magic deficiency of graphs, J. Combin. Math. Combin. Comput. 55 (2005), 17-31.

[7] R. M. Figueroa-Centeno, R. Ichishima and F. A. Muntaner-Batle, On the super edge-magic deficiency of graphs, Ars Combin. 78 (2006), 33-45.

[8] A. Kotzig and A. Rosa, Magic valuaton of finite graphs, Canad. Math. Bull. 13(4) (1970), 451-461. 
[9] A. A. G. Ngurah and E. T. Baskoro, On magic and antimagic total labelings of generalized Petersen graph, Util. Math. 63 (2003), 97-107.

[10] A. A. G. Ngurah, R. Simanjuntak and E. T. Baskoro, On the super edge-magic deficiencies of graphs, Australas. J. Combin. 40 (2008), 3-14.

[11] G. Santhosh and G. Singh, A note on the super edge-magic deficiency of graphs, Far East J. Appl. Math. 24 (2006), 233-242.

${ }^{1}$ Department of Mathematical Sciences, United ARAB EMIRATES University, P. O. Box 15551, Al Ain, United Arab Emirates

${ }^{2}$ Department of Mathematics, School of Natural Sciences (SNS), National University of Sciences and Technology (NUST), SeCtor H-12, Islamabad, PAKIstan

Email address: imrandhab@gmail.com

${ }^{3}$ Department of Mathematics, The University of Lahore, Pakpattan Campus, Pakistan Email address: aqbaig1@gmail.com

${ }^{4}$ Department of Applied Mathematics and Informatics, Technical University, Košice, Slovakia

Email address: andrea.fenovcikova@tuke.sk 